\title{
Studies on Metal Chelating Property and Pharmaceutical Applications of Curcumin Metal Complex.
}

\author{
Dr. M.Amutha ${ }^{1}$, J.Sivasakthi ${ }^{1}$, Dr.A.Gubendran ${ }^{2}$ P.Dhanasekaran ${ }^{2}$ \\ R.Imayatharasi ${ }^{2}$, \\ ${ }^{I}$ Assistant professor, Department of chemistry V.V.Vanniaperumal college for women Virudhunagar, \\ Tamilnadu, India. \\ ${ }^{I}$.M.Sc Scholar Department of chemistry V.V.Vanniaperumal college for women Virudhunagar, Tamilnadu. \\ ${ }^{2}$.Associate professor Department of chemistry Saraswathi Narayanan College, Madurai, Tamilnadu, India. \\ ${ }^{2}$. M.Phil Scholars, Department of chemistry Saraswathi Narayanan College, Madurai, Tamilnadu, India.
}

\subsection{Curcumin}

\section{Introdution}

"From kitchen to clinic" Curcumin plays a vital role in human life. Curcumin (=1,7-bis(4-hydroxy-3methoxyphenyl)-1,6-heptadiene-3,5-dione) is a component of the Indian spice turmeric, manufactured from the rhizome of the perennial herb Curcuma longa that is widely cultivated in tropical countries in South and South East Asia, especially in China and India. Curcuma longa belongs to the Zingiberaceae (ginger) family[1-5].The structure of curcumin $\left(\mathrm{C}_{21} \mathrm{H}_{20} \mathrm{O}_{6}\right)$ was first described in 1913 by Lampe and Milobedeska and shown to be feruloylmethane (Aggarwal et al., 2003). Curcumin $(=\mathrm{CurcH})$ is the major component of three curcuminoids that give turmeric its characteristic yellow color and is used as a food colorant, flavoring and additive (Figure 1$2)$. The minor curcuminoid components are demethoxycurcumin $(=\mathrm{DMCurcH})$ and bis-demethoxycurcumin $(=\mathrm{BDMCurCH})$ in which one or both $-\mathrm{OMe}$ functionalities at the outer phenol rings are removed.

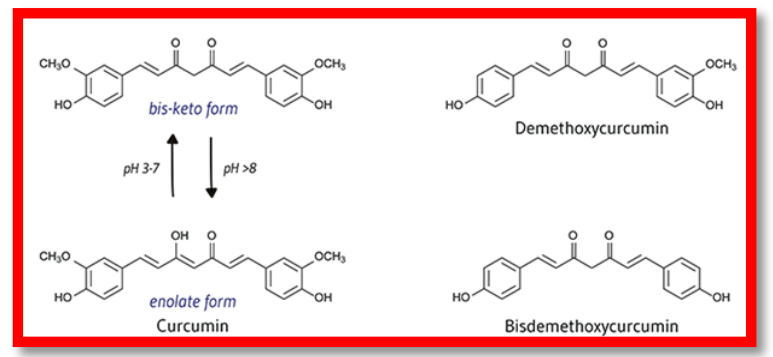

Figure 1.1 Keto enol tautomers of curcumin

\subsection{Molecular target and chelating ligand effect of curcumin}

Various studies have shown that curcumin modulates numerous targets (Figure). These include the growth factors, growth factor receptors, transcription factors,cytokines, enzymes, and genes regulating apoptosis. The chemical structure of curcumin was first identified in 1910 by Miłobędzka, von Kostanecki and LampeThrough chemical derivatization, It was clearly established the identity of curcumin as diferuloylmethane or 1,7-bis(4-hydroxy-3-methoxyphenyl)-1,6-heptadiene-3,5-dione.The two potentially useful derivatives, dicarbomethoxycurcumin and dicarboethoxycurcumin, by treatment of curcumin with two equivalents of methyl- or ethylchloroformate, respectively, in the presence of aqueous potassium hydroxide. These two derivatives are particularly valuable in curcumin chemistry as they are easily accessible in good yields and high purity[6-8].

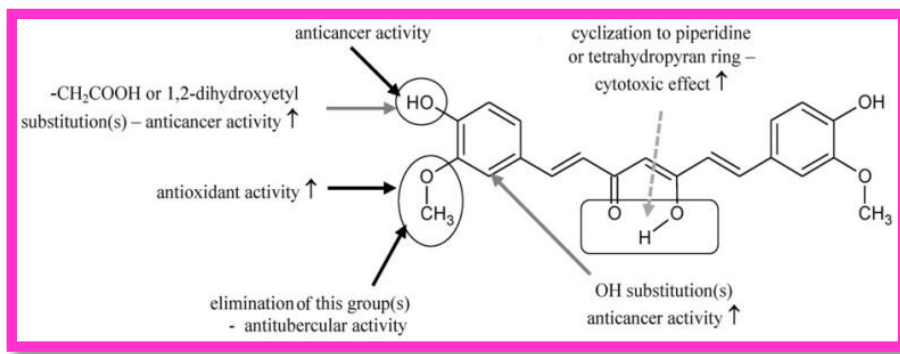

1.3 Molecular targetand chelating ligand effect of curcumin 


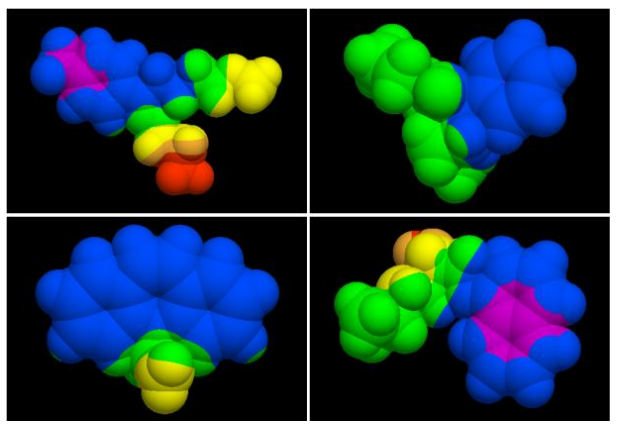

1.4Molecular targetand chelating ligand 3D effect of curcumin

\section{Materials and Methods}

2.1 Synthesis of Curcumin Fresh rhizomes were cleaned, washed with deionized water, sliced and dried in the sun for one week and again dried at $50{ }^{\circ} \mathrm{C}$ in a hot air oven for 6 hours. Dried rhizomes were cut in small pieces, powdered. Approximately $20 \mathrm{~g}$ of sample were taken and set up with various solvent from nonpolar to polar. $150 \mathrm{~mL}$ of solvent was added and extracted according to their boiling point for 6 hours. The solvents used were Hexane (b.pt $=69^{\circ} \mathrm{C}$ ), Chloroform $\left(\mathrm{B} \cdot \mathrm{P}=61^{\circ} \mathrm{C}\right.$ ), Ethyl acetate (b.pt $=77^{\circ} \mathrm{C}$ ), Methanol (b.pt $\left.=65^{\circ} \mathrm{C}\right)$, and Acetone (b.pt $=56.53^{\circ} \mathrm{C}$ ). And one sample was extracted with hexane for 2 hours and hexane extract was discarded and the powder was re-extracted with methanol for 6 hours. After completion of extraction the dark brown extract was then cooled, filtered, concentrated using rotary evaporator, and finally by vacuum suction to get a crude dried extract which was black orange in color. Each raw sample of turmeric was extracted by the same method and yield was calculated.Curcuma longa (Turmeric) rhizome were collected from Assam Lakhadong variety. All solvents / Chemicals used were of AR / HPLC grade and obtained from E-Merck. The reference standard of Curcumin was purchased from Sigma Chemicals Co. U.S.A[9-11].

\subsection{Synthesis of Curcumin- Chromium complex}

The Cr(III)-curcumin complex was synthesized by mixing equi-molar amounts of Chromium chloride (1.0 $\mathrm{mmol})$ and curcumin $(0.37 \mathrm{~g}, 10 \mathrm{mmol})$ in ethanol and the mixture was heated at $60^{\circ} \mathrm{C}$ for $1 \mathrm{~h}$ under a nitrogen atmosphere and the reaction was further continued for $2 \mathrm{~h}$ under reflux. Then the complex solution formed was concentrated and the solid residue was separated by filtration and washed several times by water/ethanol to remove unreacted curcumin.

2.3 FTIR IR spectra of curcumin and its complexes were recorded on spectrometer in $\mathrm{KBr}$ discs with resolution of $4 \mathrm{~cm}-1$ and scans of 32 . The spectral range was from 4000 to $400 \mathrm{~cm}-1$.

Electronic spectra

Electronic spectra of the ligands and their complexes were recorded in DMSO on a Thermo electron Nicolet evolution $300 \mathrm{UV}$-vis spectrophotometer.

2.4 Antimicrobial Activity of Compound on Pathogens -Well Diffusion Method Antimicrobial activity of the extract of compound was determined using well diffusion method. It was performed by sterilizing Mueller Hinton agar media. After solidification, wells were cut on the Mueller Hinton agar using corn borer. The test pathogens were swabbed onto the surface of Mueller Hinton agar plates. Wells were impregnated with $25 \mu 1$ of the test samples. The plates were incubated for $30 \mathrm{~min}$ to allow the extract to diffuse into the medium. The plates were incubated at $30^{\circ} \mathrm{C}$ for 24 hours, and then the diameters of the zone of inhibition were measured in millimeters. Each antimicrobial assay was performed in triplicate and mean values were reported.

\section{Results And Discussion}

In order to establish the relativeimportance of phenolic and enolic centre to the antimicrobial activity of curcumin,the synthesis of only 1:1 complexes were attempted even though 1:2 complexes ofcurcumin were also reported [12-13]. This was to retain the number of phenolic group as two, similar to the parent curcumin.

\section{Curcumin}

\section{Electronic spectra}

UV spectrum was recorded in the range of 300-600 nm in DMSO. Maximum absorption band of curcumin was obtained at $438 \mathrm{~nm}$ indicating the $\mathrm{n}-\mathrm{Pi}^{*}$ transition. Figure 4.1 showed the electronic spectra of curcumin. 


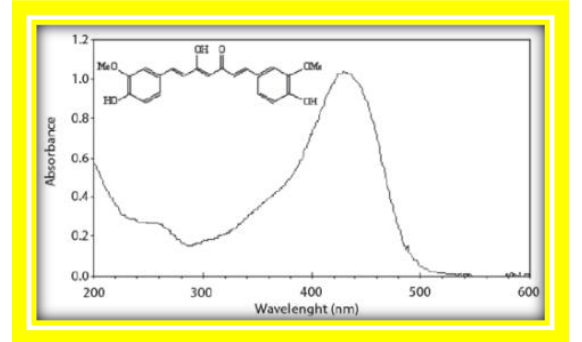

Figure 4.1 Electronic spectra of curcumin

\section{Infrared spectra}

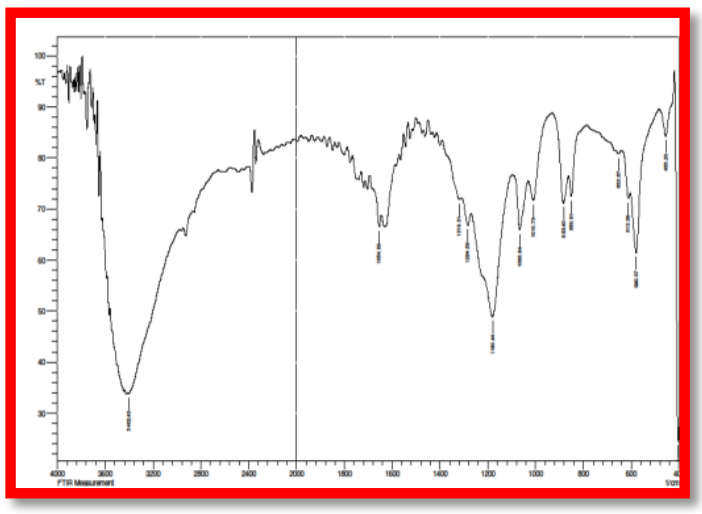

Figure 4.2IR spectra of curcumin

The strong broad absorption band centred at $3440 \mathrm{~cm}-1$ was interpreted as the result of $(\mathrm{O}-\mathrm{H})$ stretching. The peak at $2930 \mathrm{~cm}-1$ is characteristic to $\mathrm{C}-\mathrm{H})$. The sharp band at $1628 \mathrm{~cm}-1 \mathrm{can}$ be assigned to $\quad(\mathrm{C}=\mathrm{O})$. The intense band at $1500 \mathrm{~cm}-1$ may be due to $(\mathrm{C}=\mathrm{C})$. The sharp peak at $1271 \mathrm{~cm}-1$ corresponds to $(\mathrm{C}-\mathrm{O})$ of phenol. A medium intense band at $1029 \mathrm{~cm}-1$ can be ascribed to (O-CH3). The spectrum obtained was as in Fig 4.2.

\section{Curcumin - metal complex}

The UV spectra of curcumin-I exhibited apeak at $434 \mathrm{~nm}$ and in metal complex the absorption maxima was shifted tohigher region of 437-442 nm. The complex exhibited a shoulder peak in therange of (450-463 nm) indicating Curcumin Metal $\left(\mathrm{M}^{3+}\right)$ charge transfertransition. The absorption data obtained was in agreement with the data for 1:1complexes as suggested by Barik et al [13-16]. For 1:2 complex Barik et al showed anabsorption in the range of $370 \mathrm{~nm}$. Curcumin exhibit keto-enol tautomerism, theenol form that predominate in basic condition easily gets deprotonated to giveenolate ion, which is capable of forming very stable complex with a vast range ofmetal ion. In acidic condition the diketone form predominate whichcan also undergo metal chelation. The strong $\mathrm{C}=\mathrm{O}$ stretching peak observed forcurcumin at $1623 \mathrm{~cm}^{-1}$ showed a blue shift in metal complex and the valueassigned is $1606 \mathrm{~cm}-1 \mathrm{Cr}$ (III) complex. The IR data of the entire synthesized complexsuggest the chelation mode as shown in Fig. 4.4, where the ionic enol form is chelated with metal.In the IRspectrum of curcumin and its metal complexes the $\mathrm{O}-\mathrm{H}$ band of phenol do notshow considerable shift from $3433 \mathrm{~cm}-1$ hence concluded that the phenolic $\mathrm{O}-\mathrm{H}$ isnot involved in complex formation.Moreover, theappearance of new bands at $506 \mathrm{~cm}^{-1}$ corresponds to $v(\mathrm{M}-\mathrm{O})$. Also the new bands at $1380 \mathrm{~cm}^{-1}$ and $1282 \mathrm{~cm}^{-1}$ corresponds to symmetric and asymmetric stretching for $v(\mathrm{M}-\mathrm{O})$ which evidenced the participation ofthe COOion in the complexes. These facts are further supported by the appearance of bands between $1390-1456 \mathrm{~cm}^{-1}$ and $1280-1321 \mathrm{~cm}^{-1}$ attributed to vasy(COO-) and vsy(COO-).

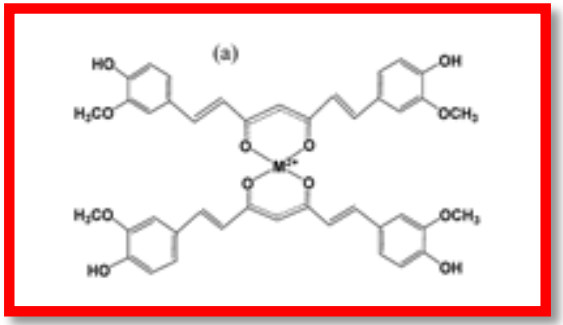

Figure 4.3 curcumin - Cr metal complex 


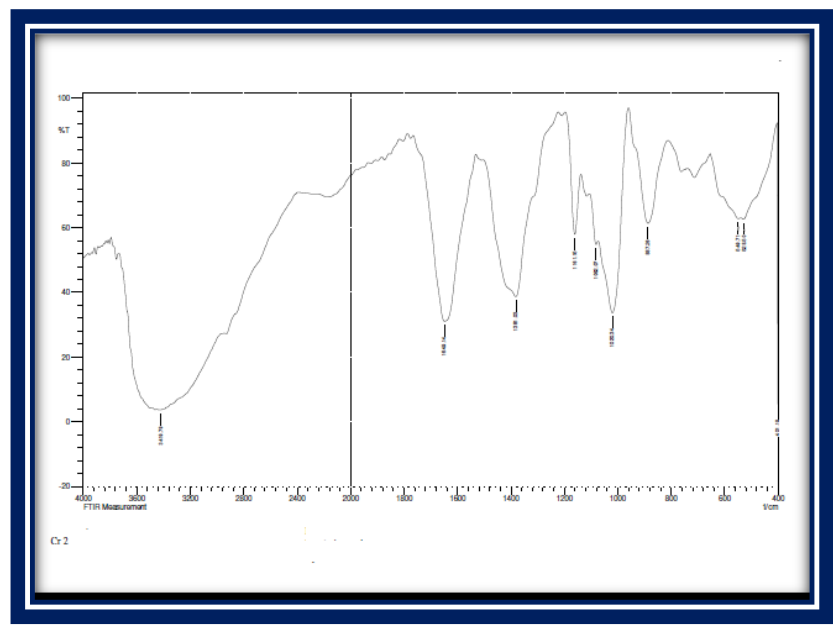

Figure 4.4 IR spectra of curcumin - Cr metal complex

\subsubsection{Thermal Analysis}

TGA was used to determine degradation temperatures and absorbedmoisture content. Curcumin was stable up to $150^{\circ} \mathrm{C}$ and the DTG peak observed at $160^{\circ} \mathrm{C}$ can be attributed to the dehydroxylation of two -OH groups and after $400^{\circ}$ Cthere is complete decomposition [12-14]. The Cr III complex showed a weight lossaround $175^{\circ} \mathrm{C}$ corresponding to loss of coordinated water (weight loss found:3.7\%, calcd $3.8 \%$ ). $\mathrm{The} \mathrm{Cr}(\mathrm{III})$ complex showed a weight loss at $165^{\circ} \mathrm{C}$ due to loss of coordinated water (weight loss found: $3.8 \%$, calcd $4.0 \%$ ).

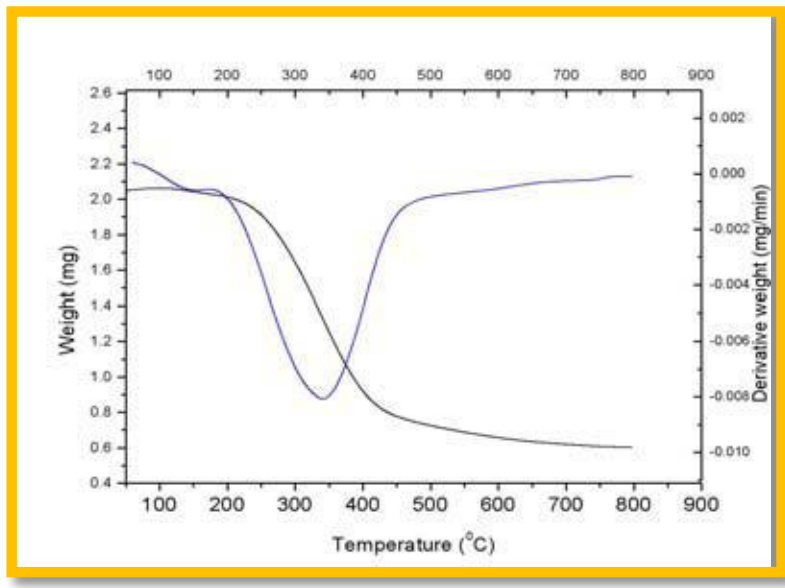

Figure 4.5 TGACurve of curcumin

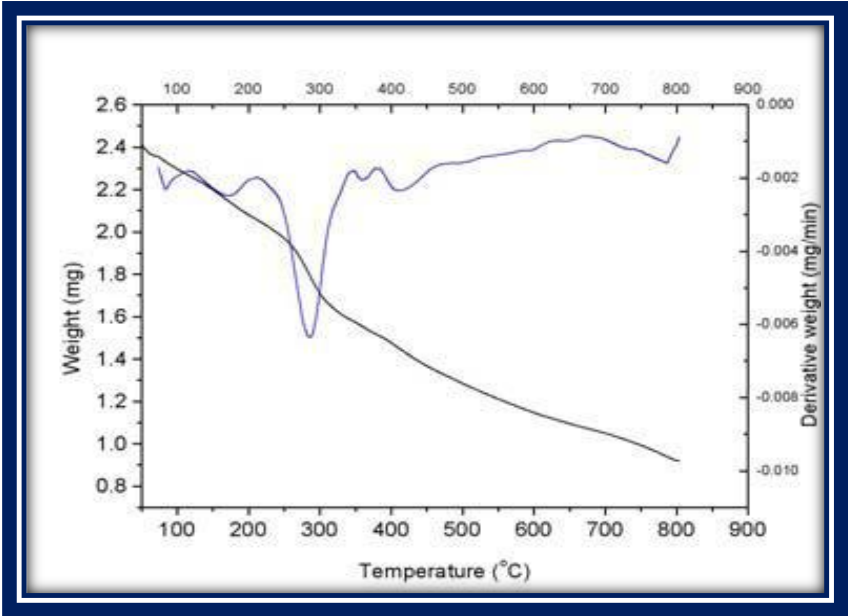

Figure 4.6 TGA curve of curcumin metal complex 


\section{Antimicrobial activity of the compound against bacterial pathogens}

Pharmaceutical applications of Cr-Curcumin complex was studied for Staphylococcus aureus, E. coli, Klebsiella pneumonia and Pseudomonas fluorescence. On the basis of MCI zone area the activity of the complex is in the order, Klebsiella pneumonia> E. coli > Staphylococcus aureus> Pseudomonas fluorescence.The following figures (1-4 )showed the antimicrobial activity for the microbes.

Plate: 1.complexagainst Staphylococcusaureus

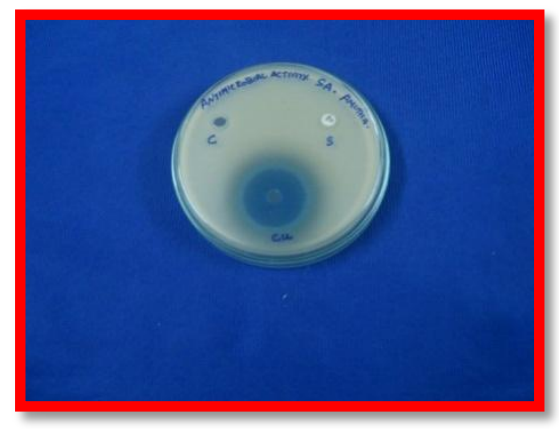

Plate: 2. complex against E.coli

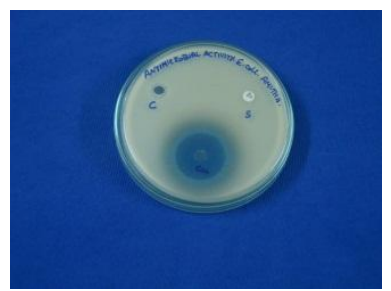

Plate: 3. complex against Klebsiella pneumonia

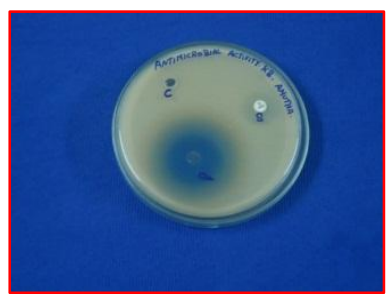

Plate: 4. complex against Pseudomonasfluorescence

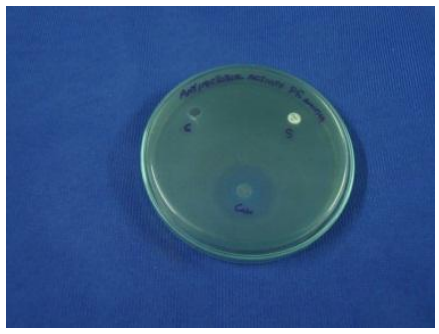

Table: 4.1. Antimicrobial activity of the compounds against microbial pathogens

\begin{tabular}{|l|l|l|l|}
\hline Test organisms & Cr & $\begin{array}{l}\text { Solvent } \\
\text { control }\end{array}$ & Standard Amp 10 $\boldsymbol{\mu g}$ \\
\hline Staphylococcus aureus & 40 & $\mathrm{NZ}$ & 16 \\
\hline E. coli & 43 & $\mathrm{NZ}$ & 14 \\
\hline Klebsiella pneumonia & 47 & $\mathrm{NZ}$ & 23 \\
\hline $\begin{array}{l}\text { Pseudomonas } \\
\text { fluorescence }\end{array}$ & 32 & $\mathrm{NZ}$ & 19 \\
\hline
\end{tabular}

Solvent used : DMSO (Dimethyl Sulphoxide)

Standard used: Ampicillin $10 \mu \mathrm{g}$. 


\section{Conclusion}

The novel Cr-Curcumin complex was synthesized and its structure was confirmed by FT-IR spectra.The interaction of curcumin and $\mathrm{Cr}(\mathrm{III})$ was the significant $\mathrm{Cr}(\text { curcumin })_{2}$. The diffuse reflectance IR spectra indicated that the complex was reasonably stable both in aqueous solution and in solid state.Pharmaceutical applications of Cr-Curcumin complex was studied for Staphylococcus aureus, E. coli, Klebsiella pneumonia and Pseudomonas fluorescence.On the basis of MCI zone area the activity of the complex is in the order, Klebsiella pneumonia> E. coli > Staphylococcus aureus> Pseudomonas fluorescence. Resultsobtained provide a promising role of Chromium- curcumin complexes in diverse biological applications especially for UTI patients. It is simple to prepare and cost-effective drug for patients.In the complex of curcumin the enolate form of curcumin ligands to the metal. The complexes have comparableantimicrobial activity to parent curcumin-I, establishing the minimal involvement ofketo-enol moiety of curcumin as the antioxidant centre and hold up the phenolic $-\mathrm{OH}$ as the prime centre for the antioxidant activity. Thus it can concludethat different parts of curcumin help in different way to accelerate its biologicalproperty. The $\mathrm{C}=\mathrm{O}$ group as metal chelator reducing oxidative stress, phenol asantioxidant centre and neutral hydrophobic conjugated hydrocarbon bridgefacilitate the penetration into the microbes-cell barrier.

\section{Reference}

[1]. Aggarwal, B.B.; Kumar, A.; Bharti, A.C. Anticancer potential of curcumin: Preclinical and clinical studies. Anticancer Res. 2003, 23, 363-398.

[2]. Wilken, R.; Veena, S.M.; Wang, M.B.; Srivatsan, E.S. Curcumin: A review of anticancer properties and therapeutic activity in head and neck squamous cell carcinoma. Mol. Cancer 2011, 10, 1-19.

[3]. Grykiewicz, G.; Silfirski, P. Curucmin and curcuminoids in quest for medicinal status. Acta Biochim. Pol. 2012, 59, 201-212.

[4]. Esatbeyoglu, T.; Huebbe, P.; Insa, M.A.; DawnChin, E.; Wagner, A.E.; Rimbach, G. Curcumin-From Molecule to Biological Function. Angew. Chem. Int. Ed. 2012, 51, 5308-5332.

[5]. Gupta, S.; Prasad, S.; Ji, H.K.; Patchva, S.; Webb, L.J.; Priyadarsini, K.I.; Aggarwal, B.B. Multitargeting by curcumin as revealed by molecular interaction studies. Nat. Prod. Rep. 2011, 28, 1937-1955.

[6]. Priyadarsini, K.I. Chemical and structural features influencing the biological activity of curcumin. Curr. Pharm. Des. 2013, 19, 2093-2100.

[7]. Vogel, H.A.; Pelletier, J. Curcumin-biological and medicinal properties. J. Pharma1815, 2, 50.

[8]. Sharma, O.P. Antioxidant activity of curcumin and related compounds. Biochem. Pharmacol. 1976, 25, 1811-1812.

[9]. Singh, S.; Aggarwal, B. Activation of transcription factor NF- $\kappa$ B is suppressed by curcumin (Diferuloylmethane). J. Biol. Chem. 1995, 270, 24995-25000.

[10]. Ramanjaneyulu, P.S.; Sayi, Y.S.; Raman, V.A.; Ramakumar, K.L. Spectrophotometric determination of boron in nuclear grade uranium compounds with curcumin and studies on effect of $\mathrm{HNO}_{3}$. J. Radioanal. Anal. Nucl. Chem. 2007, 274 , $109-114$.

[11]. Paulucci, V.P.; Couto, R.O.; Teixeira, C.C.C.; Freitas, L.A.P. Optimization of the extraction of curcumin from Curcuma longa rhizomes. Braz. J. Pharmacogn. 2013, 23, 94-100.

[12]. Lee, K.J.; Yang, H.J.; Jeong, S.W.; Ma, J.Y. Solid-phase extraction of curcuminoid from turmeric using physical process method. Korean J. Pharmacogn. 2012, 43, 250-256.

[13]. Lee, K.J.; Ma, J.Y.; Kim, Y.-S.; Kim, D.-S.; Jin, Y. High purity extraction and simultaneous high-performance liquid chromatography analysis of curcuminoids in turmeric. J. Appl. Biol. Chem. 2012, 55, 61-65.

[14]. Li, M.; Ngadi, M.O.; Ma, Y. Optimisation of pulsed ultrasonic and microwave-assisted extraction for curcuminoids by response surface methodology and kinetic study. Food Chem. 2014, 165, 29-34.

[15]. Patel, K.; Krishna, G.; Sokoloski, E.; Ito, Y. Preparative separation of curcuminoids from crude curcumin and turmeric powder by pH-zone-refining counter current chromatography. J. Liquid Chromatogr. 2000, 23, 2209-2218. 